\title{
Review Article \\ Regulation of HuR by DNA Damage Response Kinases
}

\author{
Hyeon Ho Kim, ${ }^{1,2}$ Kotb Abdelmohsen, ${ }^{1}$ and Myriam Gorospe ${ }^{1}$ \\ ${ }^{1}$ Laboratory of Cellular and Molecular Biology, NIA-IRP, NIH, Baltimore, MD 21224, USA \\ ${ }^{2}$ Samsung Biomedical Research Institute, Samsung Medical Center, Sungkyunkwan University School of Medicine, Seoul 135-710, \\ Republic of Korea \\ Correspondence should be addressed to Kotb Abdelmohsen, abdelmohsenk@grc.nia.nih.gov
}

Received 15 April 2010; Accepted 17 May 2010

Academic Editor: Ashis Basu

Copyright () 2010 Hyeon Ho Kim et al. This is an open access article distributed under the Creative Commons Attribution License, which permits unrestricted use, distribution, and reproduction in any medium, provided the original work is properly cited.

\begin{abstract}
As many DNA-damaging conditions repress transcription, posttranscriptional processes critically influence gene expression during the genotoxic stress response. The RNA-binding protein HuR robustly influences gene expression following DNA damage. HuR function is controlled in two principal ways: (1) by mobilizing HuR from the nucleus to the cytoplasm, where it modulates the stability and translation of target mRNAs and (2) by altering its association with target mRNAs. Here, we review evidence that two main effectors of ataxia-telangiectasia-mutated/ATM- and Rad3-related (ATM/ATR), the checkpoint kinases Chk1 and Chk2, jointly influence HuR function. Chk1 affects HuR localization by phosphorylating (hence inactivating) Cdk1, a kinase that phosphorylates HuR and thereby blocks HuR's cytoplasmic export. Chk2 modulates HuR binding to target mRNAs by phosphorylating HuR's RNA-recognition motifs (RRM1 and RRM2). We discuss how HuR phosphorylation by kinases including Chk1/Cdk1 and Chk2 impacts upon gene expression patterns, cell proliferation, and survival following genotoxic injury.
\end{abstract}

\section{Introduction}

Damage to the cellular DNA can transiently inhibit the activity of RNA polymerase II at a time when DNA damage response (DDR) proteins and DNA repair proteins are critically needed [1]. As transcription is reduced, there is increased need to regulate the production of proteins from the pre-existing pool of mRNAs. Two main posttranscriptional mechanisms control protein expression following genotoxic damage: mRNA turnover and translational regulation $[2,3]$. These two sets of events are potently influenced by RNA-binding proteins (RBPs) and noncoding RNAs (primarily microRNAs), which interact with mRNAs and modulate their half-lives and translation rates [4-6].

During the DDR, several RBPs showing altered levels or subcellular localization have been implicated in controlling gene expression. For example, many RBPs that control RNA metabolism showed altered expression in response to ionizing radiation (IR) and ultraviolet radiation (UV) [7]; in another study, several members of the heterogeneous ribonuclear protein (hnRNP) family were found to participate in the response to IR [8]. Specific RBPs have also been shown to participate in different types of DDR; for example, the RBPs AU-binding factor 1 (AUF1) and T cell-restricted intracellular antigen-related protein (TIAR) controlled the expression of the growth arrest- and DNA damage-inducible (gadd)45a protein in response to alkylating DNA damage [9], the RBPs nucleolin and nucleophosmin participated in the cellular responses to IR and UV [10], and the RBP Sam68 modulated alternative splicing following DNA damage [11]. One of the best characterized RBPs that control expression of DDR genes, HuR, is the subject of this review.

\section{Stress-Response Protein HuR}

$\mathrm{HuR}$ is the ubiquitous member of the embryonic lethal abnormal vision (ELAV)/Hu family of RBPs, which also contains the primarily neuronal members $\mathrm{HuB}, \mathrm{HuC}$, and $\mathrm{HuD}$ [12]. Although HuR is predominantly nuclear, its translocation to the cytoplasm is linked to its ability to stabilize target mRNAs and/or modulate their translation $[13,14]$. The 326-aa long HuR binds target mRNAs through its three RNA recognition motifs (RRMs); located between RRM2 and RRM3 is a hinge region that encompasses a nucleocytoplasmic shuttling sequence (HNS, spanning 


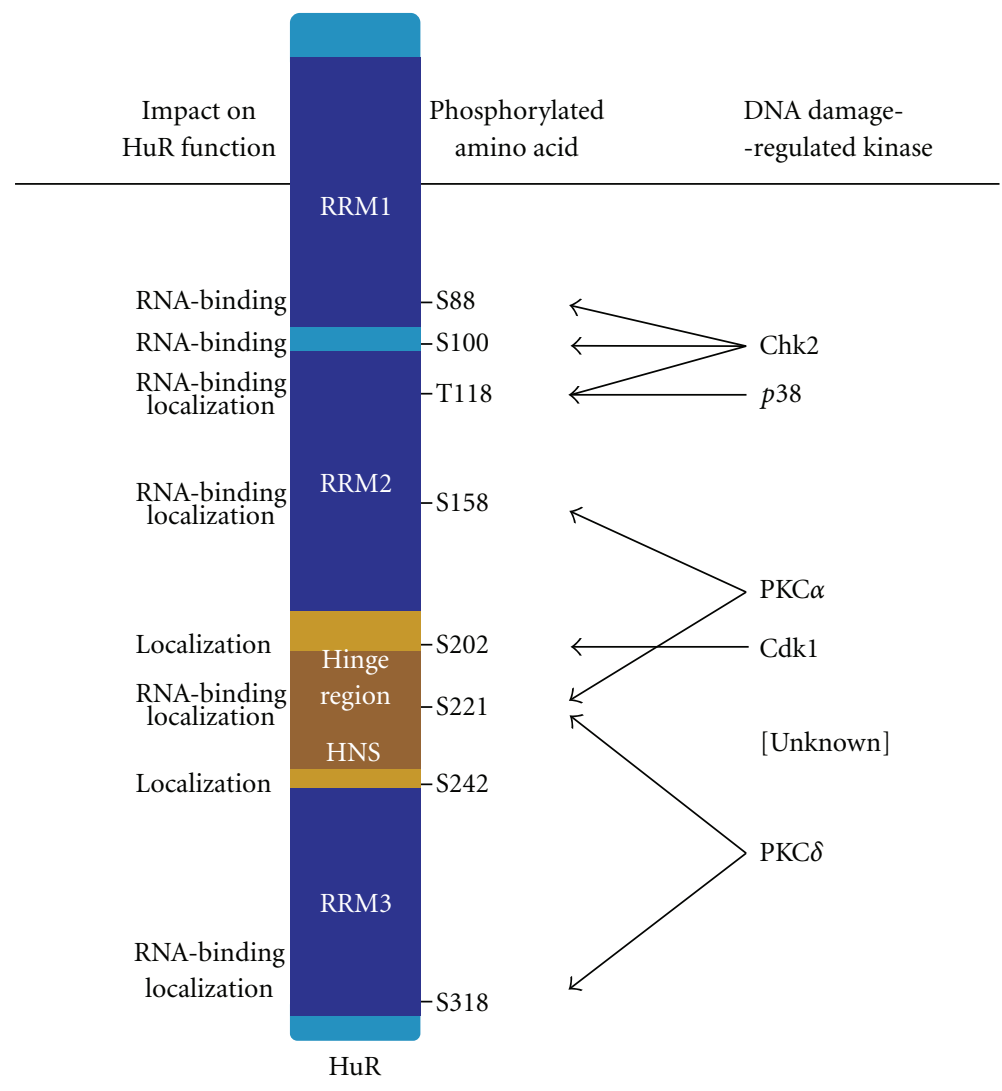

Figure 1: Sites of HuR phosphorylation by DNA damage-inducible kinases. Schematic of HuR depicting the RNA recognition motifs (RRMs, dark blue), the hinge region (brown) with the HuR nucleocytoplasmic shuttling sequence (HNS), the sites of phosphorylation (under "Phosphorylated Amino Acids"), and the DNA Damage-Regulated Kinases responsible, including an unknown kinase predicted to phosphorylate S242. The consequences of HuR phosphorylation at the different sites are indicated under "Impact on HuR Function". More details in the text.

residues 205-237 [15]) (Figure 1). The nuclear export of HuR is mediated by its association with transportin $1(\operatorname{Trn} 1)$ and Trn2 [16] and with nuclear ligands pp32 and APRIL, which contain nuclear export signals that are recognized by the export receptor CRM1 $[17,18]$.

HuR target mRNAs encode many proteins implicated in the cellular response to DNA damage, including tumor suppressors ( $\mathrm{p} 53, \mathrm{pVHL})$, cyclins (A, B1, and D1), protooncogenes (c-fos, c-myc), growth factors (VEGF), cytokines (TGF- $\beta$, TNF- $\alpha$ ), cyclin-dependent kinase (cdk) inhibitors (p21, p27), antiapoptotic factors [prothymosin $\alpha$ (ProT $\alpha$ ), $\mathrm{Bcl}-2$, and Mcl-1], and signaling molecules like the mitogenactivated protein (MAP) kinase phosphatase MKP-1 [1930] (Table 1); most of these transcripts contain one or several copies of a U-rich RNA signature motif [31]. Given the functions of the proteins encoded by HuR-regulated mRNAs, HuR has been implicated in processes such as carcinogenesis, proliferation, immune function, differentiation, and responsiveness to oxidative and genotoxic damage [14, 26, 32-38].

With a few exceptions $[38,44]$, acute changes in HuR function do not involve changes in protein abundance but rely instead on two regulatory steps: (1) the subcellular localization of $\mathrm{HuR}$ and (2) the interaction of $\mathrm{HuR}$ with target mRNAs. In response to DNA-damaging stresses, the past few years have uncovered a signaling pathway that jointly affects both of these processes, HuR's subcellular distribution and its interaction with target transcripts. DNA damage is recognized by sensor proteins, such as the Rad9Rad1-Hus1 complex (also termed "9-1-1 complex") that recognizes certain types of DNA damage and is mediated by proteins such as those that comprise the Mre11-Rad50Nbs1 complex (MRN), which recruits the transducer protein DNA damage-activated ataxia telangiectasia mutated (ATM) to sites of DNA damage [45]. The transducer proteins include the kinases ATM and ATM- and Rad3-related (ATR); ATM/ATR phosphorylates and thereby activates the checkpoint kinases Chk1 and Chk2, which control HuR cytoplasmic abundance and RNA binding, respectively. ATM is primarily activated by double-strand breaks in DNA, such as those caused by IR [46] while ATR is activated in response to other damaging agents, including UV, alkylating agents, and chemical inhibitors of DNA replication [47, 48], but there is extensive evidence that both kinases work in tandem [49]. As these kinases are essential for genomic integrity, deficiencies in ATM/ATR and other components of DNA damage checkpoints cause debilitating diseases such as ataxia telangiectasia, Fanconi's anemia, and Seckel syndrome, 
TABLE 1: HuR target mRNAs showing altered expression after DNA damage. Partial list of HuR target mRNAs encoding proteins that change following DNA damage (first column), the region of interaction with HuR (second column), and the genotoxic damage that was shown to affect HuR regulation of the mRNA (third column); "n.r.": no reported. The HuR kinases linked to the regulation of the mRNAs in the first column are indicated (fourth column).

\begin{tabular}{|c|c|c|c|c|c|}
\hline & $\begin{array}{l}\text { Target mRNA after } \\
\text { DNA damage }\end{array}$ & Binding region & $\begin{array}{l}\text { DNA damage conditions affecting } \\
\text { regulation by HuR }\end{array}$ & HuR Kinase & References \\
\hline \multirow{16}{*}{ mRNA stabilization } & $c-f o s$ & $3^{\prime} \mathrm{UTR}$ & n.r. & n.r. & {$[-]$} \\
\hline & $p 21$ & $3^{\prime} \mathrm{UTR}$ & UVC, arsenite, IR & Chk2, p38 & {$[27,39]$} \\
\hline & cyclin $A 2$ & $3^{\prime} \mathrm{UTR}$ & $\mathrm{H}_{2} \mathrm{O}_{2}$ & Chk2, Cdk1 & {$[27,29]$} \\
\hline & cyclin B1 & $3^{\prime} \mathrm{UTR}$ & $\mathrm{H}_{2} \mathrm{O}_{2}$ & n.r. & {$[40]$} \\
\hline & cyclin D1 & $3^{\prime} \mathrm{UTR}$ & UVC & Chk2 & [27] \\
\hline & iNOS & $3^{\prime} \mathrm{UTR}$ & n.r. & n.r. & {$[-]$} \\
\hline & $V E G F$ & $3^{\prime} \mathrm{UTR}$ & n.r. & n.r. & {$[-]$} \\
\hline & SIRT1 & $3^{\prime} \mathrm{UTR}$ & $\mathrm{H}_{2} \mathrm{O}_{2}$ & Chk2 & {$[27]$} \\
\hline & $T N F-\alpha$ & $3^{\prime} \mathrm{UTR}$ & n.r. & n.r. & {$[-]$} \\
\hline & $b c l-2$ & $3^{\prime} \mathrm{UTR}$ & n.r. & Cdk1 & {$[28]$} \\
\hline & $m c l-1$ & $3^{\prime} \mathrm{UTR}$ & n.r. & Cdk1 & {$[28]$} \\
\hline & $C O X-2$ & $3^{\prime} \mathrm{UTR}$ & n.r. & PKC, p38 & {$[41,42]$} \\
\hline & $u P A$ & $3^{\prime} \mathrm{UTR}$ & n.r. & n.r. & {$[-]$} \\
\hline & $u P A R$ & $3^{\prime} \mathrm{UTR}$ & n.r. & n.r. & {$[-]$} \\
\hline & $I L-3$ & $3^{\prime} \mathrm{UTR}$ & n.r. & n.r. & {$[-]$} \\
\hline & $M K P-1$ & 3'UTR & $\mathrm{H}_{2} \mathrm{O}_{2}$ & Cdk1 & [43] \\
\hline \multirow{5}{*}{$\uparrow$ Translation } & $p 53$ & $3^{\prime} \mathrm{UTR}$ & UVC & n.r. & {$[-]$} \\
\hline & ProT $\alpha$ & $3^{\prime} \mathrm{UTR}$ & UVC & Chk2, Cdk1 & [29] \\
\hline & cytochrome c & $3^{\prime} \mathrm{UTR}$ & n.r. & Chk2 & {$[27]$} \\
\hline & $M K P-1$ & $3^{\prime} \mathrm{UTR}$ & $\mathrm{H}_{2} \mathrm{O}_{2}$ & Cdk1 & [29] \\
\hline & $H I F-1 \alpha$ & $3^{\prime} \mathrm{UTR}$ & n.r. & Cdk1 & {$[29]$} \\
\hline \multirow{5}{*}{$\downarrow$ Translation } & $p 27$ & $5^{\prime} \mathrm{UTR}$ & n.r. & n.r. & {$[-]$} \\
\hline & $I G F-I R$ & $5^{\prime} \mathrm{UTR}$ & n.r. & n.r. & {$[-]$} \\
\hline & Wnt5a & 3'UTR & n.r. & n.r. & {$[-]$} \\
\hline & $H u R$ & $3^{\prime} \mathrm{UTR}$ & n.r. & n.r. & {$[-]$} \\
\hline & $c-M y c$ & 3'UTR & n.r. & n.r. & {$[-]$} \\
\hline
\end{tabular}

thereby contributing to premature aging and carcinogenesis $[50,51]$. Given that HuR target transcripts encode proteins implicated in the DDR, HuR control by ATM/ATR is rising as a major gene regulatory paradigm in the pathophysiology of DNA damage (Figure 2). Consequently, even in the presence of normal HuR levels in the cell, HuR's ability to regulate DDR gene expression posttranscriptionally is impaired in cells with aberrant ATM/ATR signaling.

\section{Regulation of HuR by ATM/ATR $\rightarrow$ Chk1 $\dashv$ Cdk1}

During DDR such as that resulting from exposure to UV, oxidants, or IR, Chk1 is phosphorylated by ATM/ATR at serine (S)317 and S345 [52]. Chk1 plays a pivotal role in the regulation of the cell division cycle by phosphorylating proteins such as the cyclin-dependent kinase 1 (Cdk1, also named Cdc2). ATM/ATR $\rightarrow$ Chk1 signaling leads to the inactivation of a dual-specificity phosphatase, Cdc25, which consists of three members (A, B, and C). Chk1 phosphorylates $\mathrm{Cdc} 25 \mathrm{~A}$ at $\mathrm{S} 76$, a modification that triggers the degradation of Cdc25A via SCF $\beta$-TRCP-mediated ubiquitination [53]. Chk1 also associates with Cdc25B and Cdc25C and inactivates these phosphatases through phosphorylation at S309/323 and S216, respectively, in turn causing their nuclear exclusion through association with 14-3-3 [54]. Cdk1 is fully activated in two steps: by phosphorylation at threonine (T) 161 via the kinase Cdk7 and by dephosphorylation of phosphor- (p-) thyrosine (Y)15 via the phosphatase Cdc25. Thus, by inhibiting Cdc25, ATM/ATR $\rightarrow$ Chk1 inactivates Cdk1. Additionally, Chk1 activates the kinase Wee1, which is responsible for the inhibitory phosphorylation of Cdk1 at Y15 [55]. As recently reported, during mitosis Cdk1 phosphorylates Chk1 at S286 and S301; the mitotic phosphorylation of Chk1 is accompanied by the translocation of Chk1 to the cytoplasm [56]. Phosphorylation of Chk1 resulting in its removal from chromatin has been shown to modify cytoplasmic substrates and plays a role at the centrosome during cell division [57]. 


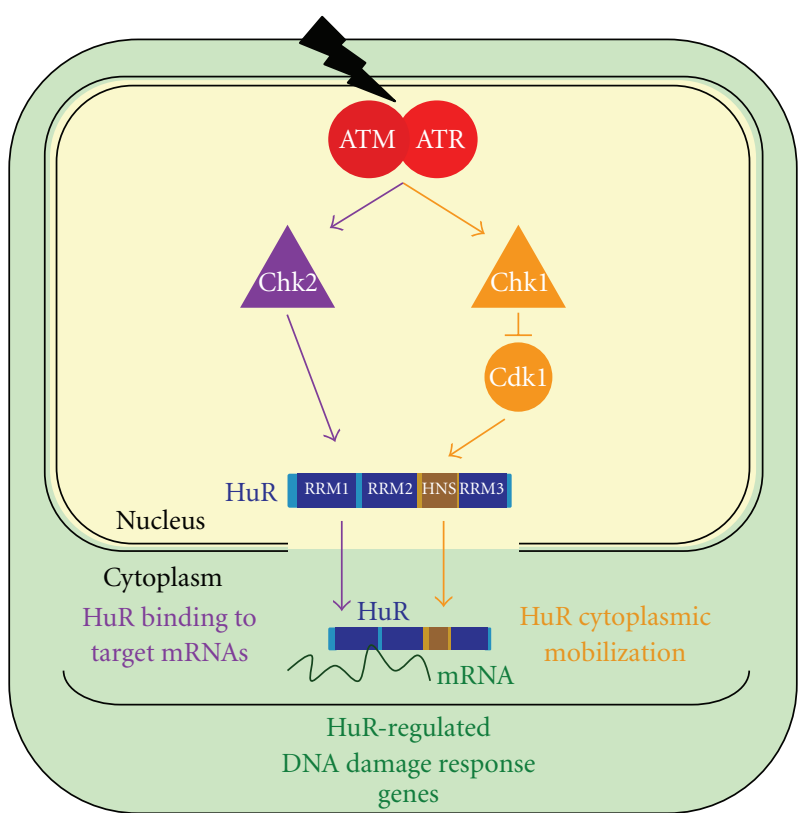

FIgURE 2: Regulation of HuR function by ATM/ATR $\rightarrow$ Chk1/Chk2. ATM/ATR regulates HuR function through the activation of Chk1 and Chk2. Active Chk1 phosphorylates (and hence inactivates) Cdk1, a kinase that phosphorylates HuR at S202; in turn, unphosphorylated $\mathrm{HuR}(\mathrm{S} 202)$ can be transported to the cytoplasm (orange). Active Chk2 phosphorylates HuR at S88, S100, and T118 (at RRM1 and RRM2); in turn, HuR association with target mRNAs is altered (purple). Jointly, ATM/ATR $\rightarrow$ Chk1/Chk2 modulates the amount of $\mathrm{HuR}$ in the cytoplasm and its interaction with target mRNAs (green).

The cellular DDR dynamically regulates the subcellular presence of HuR. Although predominantly nuclear, exposure to UV or oxidants triggers the accumulation of HuR in the cytoplasm $[20,24,43]$, where it modulates the stability and/or translation of numerous target mRNAs, as explained above. We recently reported that HuR was a direct substrate for Cdk1, which phosphorylated HuR at S202 [29]. HuR subcellular localization during the cell division cycle followed fluctuations in Cdk1 activity [29]. The reduction in Cdk1 activity that followed UV irradiation of HeLa cells resulted in the loss of HuR phosphorylation at S202, which in turn promoted the cytoplasmic accumulation of HuR. HuR translocation following Cdk1 inhibition was linked to the nuclear interaction of p-HuR(S202) and 14-3-3 [29]. Inhibition or silencing of Cdk1 enhanced the cytoplasmic level of $\mathrm{HuR}$ and increased its interaction with target mRNAs, including those that encode anti-apoptotic proteins like Bcl-2, Mcl-1, and prothymosin- $\alpha$; therefore, lowering Cdk1 also diminished the proapoptotic influence of etoposide or staurosporine. Given that DNA damage triggered by many agents reduces Cdk1 activity and increases the cytoplasmic presence of HuR, it is likely that the ATM/ATR $\rightarrow$ Chk1 $\dashv$ Cdk1 pathway is broadly responsible for controlling the cytoplasmic levels of HuR after different types of DDR.
Other DNA damage-activated pathways also affect HuR localization through Cdk1. Activation of the MAP kinase (MAPK) p38 by DNA damage phosphorylates Cdc25B and thus triggers it for degradation. In this manner, p38 affects Cdk1 levels through its influence on Cdc25B abundance. DNA damage induces the cleavage of $\mathrm{PKC} \delta$ and generates a constitutively active catalytic fragment termed $\mathrm{PKC} \delta$-cat. $\mathrm{PKC} \delta$-cat can also phosphorylate $\mathrm{Cdk} 1$ at Y15, thereby inactivating Cdk1 and inducing G2/M arrest. Moreover, $\mathrm{PKC} \delta$ can phosphorylate directly HuR at S221 and S318 (see below), triggering the cytoplasmic translocation of HuR [58]. Overall, DNA damage inactivates Cdk1, which increases cytoplasmic HuR level and thus enhances mRNA stability and translation of DNA damage response proteins.

\section{Regulation of HuR by ATM/ATR $\rightarrow$ Chk2}

One of the main roles of the ATM/ATR $\rightarrow$ Chk2 pathway is to induce cell cycle arrest, allowing cells to repair damaged DNA [59]; see [60] for a recent review on Chk2 and Chk1. Activated Chk2 phosphorylates downstream effectors such as p53, BRCA1, and Cdc25 and Cdc25A, which are involved in cellular processes such as apoptosis, DNA repair, and growth arrest [61].

Exposure of human diploid fibroblasts to genotoxic doses of hydrogen peroxide $\left(\mathrm{H}_{2} \mathrm{O}_{2}\right)$ activated Chk2, which in turn phosphorylated HuR [27]. HuR phosphorylation by Chk2 triggered the dissociation of the mRNA encoding the longevity and stress-response protein SIRT1 from HuR ribonucleoprotein (RNP) complexes; this dissociation rendered the SIRT1 mRNA unstable and triggered a decrease in the abundance of SIRT1 mRNA and protein. Three putative Chk2 phosphorylation sites were identified: HuR residues S88, S100, and T118. In human diploid fibroblasts, mutating S100 to a nonphosphorylatable residue (S100A) promoted the continued association of SIRT1 mRNA with HuR after oxidative damage, indicating that phosphorylation at residue S100 (located between RRM1 and RRM2) was critical for dissociation of the mRNA [27]. A more stable target transcript, the prothymosin $\alpha$ (PTMA) mRNA, also showed increased binding to $\mathrm{HuR}(\mathrm{S} 100 \mathrm{~A})$ compared to wildtype $\mathrm{HuR}$ following $\mathrm{H}_{2} \mathrm{O}_{2}$ treatment. Interestingly, mutation of T118 (located within RRM2) to a nonphosphorylatable site (T118A) generally showed reduced binding to all target mRNAs, suggesting that phosphorylation at T118 enhanced HuR binding to target mRNAs. Additional studies are needed to elucidate if other DNA-damaging agents also act upon Chk2 to phosphorylate HuR and how these modifications affect $\mathrm{HuR}$ function following genotoxic stress. Further work is also necessary to investigate how other HuR target mRNAs are regulated following HuR phosphorylation by Chk2.

Unexpectedly, HuR phosphorylation by Chk2 in response to heat shock helped to prevent its degradation in this stress paradigm [38]. Following heat shock, the nonphoshorylatable HuR mutants (S88A, S100A, and T118A) were more labile while HuR phosphomimic mutants (S88D, S100D, and T118D) were more resistant 
to degradation [38]. Although details of this process await further analysis, Chk2 phosphorylation of HuR appeared to block HuR proteolysis mediated by ubiquitination at $\mathrm{HuR}$ residue K182 [38]. Whether DNA damage also helps to increase HuR stability via Chk2-mediated phosphorylation also warrants careful consideration.

In addition, since Chk2 phosphorylates HuR, and Chk2 mutations influence Chk2 function, it is important to study in detail the influence of Chk2 upon HuR function on target mRNAs, just as was done for SIRT1 mRNA [27]. Chk2 was found to be mutated in the Li-Fraumeni cancer syndrome and in cancer $[62,63]$; these mutations modified Chk2's ability to interact with substrates, Chk2 kinase activity, and Chk2 subcellular localization $[59,64]$. How the role of $\mathrm{HuR}$ in gene expression is affected in Chk2 mutant cells remains unclear and will be an important aim of future studies.

\section{Other HuR Kinases Regulated by DNA Damage}

Genotoxic damage also activates additional kinases that control HuR function, including protein kinase C (PKC) and the MAPK p38. Although less is known about their influence on HuR function after DNA damage, they are also expected to be intimately linked to this response (Figure 1).

5.1. PKC. Protein kinase $\mathrm{C}(\mathrm{PKC}) \alpha$ was reported to phosphorylate HuR at S158 and S221 while PKC $\delta$ was phosphorylated HuR at S221 and S318 [41, 58, 65, 66]. PKC $\alpha$ and PKC $\delta$ were implicated in the cytoplasmic export of HuR, its enhanced association with target transcripts (e.g., COX2, cyclin D1, and cyclin A mRNAs), and their stabilization $[41,58,65,66]$. Doller and coworkers primarily examined the effect of angiotensin II (AngII) in human mesangial cells, uncovering a complex set of regulatory features. However, PKC is a bona fide DNA damage response kinase $[39,67]$. The influence of PKC on HuR-modulated gene expression is a promising area for future study.

5.2. $p 38$. The MAPK $\mathrm{p} 38$ plays a key role in the growth arrest that follows exposure to DNA-damaging agents [68-70]. An important mediator of this effect is the cdk inhibitor p21, whose levels increase in response to genotoxins such as IR. The Nebreda laboratory recently showed that following IR, p38 phosphorylated HuR at T118, leading to the cytoplasmic accumulation of $\mathrm{HuR}$, and increased the binding of $\mathrm{HuR}$ to $p 21$ mRNA. p21 mRNA was thus stabilized, leading to increased expression of $\mathrm{p} 21$ protein and to the activation of the G1/S checkpoint [71]. Inhibiting p38 or using the non-phosphorylatable mutant $\mathrm{HuR}(\mathrm{T} 118 \mathrm{~A})$ prevented the p38-mediated increase in p21 expression after IR, which abrogated the G1/S arrest. The effect of p38 upon HuR translocation and binding to target mRNAs appears to require the $\mathrm{p} 38$ downstream substrate MAPKAPK-2 (MK2), as shown in cells responding to taxanes or oxidants [42, 72], although MK2 does not appear to phosphorylate HuR directly. While a direct influence of p38 on HuR after $\mathrm{H}_{2} \mathrm{O}_{2}$ has not been studied to date, the mutant $\mathrm{HuR}(\mathrm{T} 118 \mathrm{~A})$ also showed reduced binding to p21 mRNA in $\mathrm{H}_{2} \mathrm{O}_{2}$-treated cells [27], suggesting that $\mathrm{H}_{2} \mathrm{O}_{2}$-activated p38 could similarly change HuR binding to target mRNAs.

5.3. Additional Kinases Affecting HuR Function. The AMPactivated protein kinase (AMPK) does not phosphorylate HuR directly, but it phosphorylates and enhances the acetylation of importin $\alpha 1$ [42]; in turn, importin $\alpha 1$ favors the nuclear import of HuR. Stress conditions that reduce AMPK activity can suppress this import pathway, thus allowing cytoplasmic HuR to accumulate [73]. How DNA damage affects importin $1 \alpha$-mediated localization of HuR remains to be tested directly. Finally, an as-yet unidentified kinase was reported to phosphorylate HuR at S242, promoting its nuclear retention $[40,74]$ (Figure 1).

\section{Concluding Remarks}

HuR function is regulated by several kinases that play central roles in the DNA damage response, notably those in the ATM/ATR $\rightarrow$ Chk1/Chk2 pathway. Together with PKC and p38, these signaling cascades govern HuR's cytoplasmic abundance and interaction with target mRNAs. It is intriguing that these kinases converge on a shared substrate protein, HuR, which potently influences gene expression patterns posttranscriptionally. A deeper understanding of the signaling pathways that govern HuR function is helping to elucidate HuR's role in the overall DDR and in the gene expression changes that ensue.

The emergence of HuR a key effector of the DDR program has important biological and clinical implications. First, it suggests that modulation of gene expression by $\mathrm{ATM} / \mathrm{ATR} \rightarrow \mathrm{Chk} 1 / \mathrm{Chk} 2$ is strongly influenced by HuR; consequently, cells with impaired ATM/ATR $\rightarrow$ Chk1/Chk2 signaling could express different subsets of proteins due to aberrant $\mathrm{HuR}$ function (localization and RNA-binding activity). Second, since lowering HuR levels or preventing its phosphorylation reduced cell survival following genotoxic damage $[26,27,75]$, HuR could be a promising target for therapeutic intervention. Third, the high levels of HuR observed in many cancers (which appear to underlie HuR's role in tumorigenesis $[76,77]$ ) could engender an effective DDR in cancer cells. Thus, cancer treatments that do not rely on DNA damage might be advantageous when tumoral HuR levels are elevated.

In sum, the posttranscriptional control of gene expression is particularly important during the DDR, when transcription may be depressed to avoid the synthesis of aberrant transcripts. Through post-translational modification by the kinases reviewed here (primarily ATM/ATR $\rightarrow$ Chk1/Chk2, but also PKC and p38), HuR helps to orchestrate protein expression from pre-existing mRNAs following damage to DNA. In this capacity, HuR is a key factor that helps to ensure the maintenance of cellular homeostasis following genotoxic injury. 


\section{Abbreviations}

ATM: Ataxia-telangiectasia-mutated

ATR: ATM- and Rad3-related

ELAV: Embryonic lethal abnormal vision

IR: Ionizing radiation

UV: Ultraviolet irradiation

RBP: RNA-binding protein

UTR: Untranslated region.

\section{Acknowledgments}

This work was supported by the Intramural Research Program of the National Institute on Aging and National Institutes of Health.

\section{References}

[1] J. Q. Svejstrup, "Mechanisms of transcription-coupled DNA repair," Nature Reviews Molecular Cell Biology, vol. 3, no. 1, pp. 21-29, 2002.

[2] P. Mitchell and D. Tollervey, "mRNA stability in eukaryotes," Current Opinion in Genetics and Development, vol. 10, no. 2, pp. 193-198, 2000.

[3] G. Orphanides and D. Reinberg, "A unified theory of gene expression," Cell, vol. 108, no. 4, pp. 439-451, 2002.

[4] M. J. Moore, "From birth to death: the complex lives of eukaryotic mRNAs," Science, vol. 309, no. 5740, pp. 1514$1518,2005$.

[5] J. D. Keene, "RNA regulons: coordination of posttranscriptional events," Nature Reviews Genetics, vol. 8, no. 7, pp. 533-543, 2007.

[6] D. P. Bartel, "MicroRNAs: target recognition and regulatory functions," Cell, vol. 136, no. 2, pp. 215-233, 2009.

[7] K. E. Rieger and G. Chu, "Portrait of transcriptional responses to ultraviolet and ionizing radiation in human cells," Nucleic Acids Research, vol. 32, no. 16, pp. 4786-4803, 2004.

[8] B. Haley, T. Paunesku, M. Protic, and G. E. Woloschak, "Response of heterogeneous ribonuclear proteins (hnRNP) to ionising radiation and their involvement in DNA damage repair," International Journal of Radiation Biology, vol. 85, no. 8, pp. 643-655, 2009.

[9] A. Lal, K. Abdelmohsen, and R. Pullmann et al., "Posttranscriptional derepression of GADD $45 \alpha$ by genotoxic stress," Molecular Cell, vol. 22, no. 1, pp. 117-128, 2006.

[10] C. Yang, D. A. Maiguel, and F. Carrier, "Identification of nucleolin and nucleophosmin as genotoxic stress-responsive RNA-binding proteins," Nucleic Acids Research, vol. 30, no. 10, pp. 2251-2260, 2002.

[11] R. Busà, R. Geremia, and C. Sette, "Genotoxic stress causes the accumulation of the splicing regulator Sam68 in nuclear foci of transcriptionally active chromatin," Nucleic Acids Research, vol. 38, no. 9, pp. 3005-3018, 2010.

[12] M. N. Hinman and H. Lou, "Diverse molecular functions of Hu proteins," Cellular and Molecular Life Sciences, vol. 65, no. 20, pp. 3168-3181, 2008.

[13] J. D. Keene, "Why is Hu where? Shuttling of early-responsegene messenger RNA subsets," Proceedings of the National Academy of Sciences of the United States of America, vol. 96, no. 1, pp. 5-7, 1999.
[14] C. M. Brennan and J. A. Steitz, "HuR and mRNA stability," Cellular and Molecular Life Sciences, vol. 58, no. 2, pp. 266277, 2001.

[15] X. C. Fan and J. A. Steitz, "HNS, a nuclear-cytoplasmic shuttling sequence in HuR," Proceedings of the National Academy of Sciences of the United States of America, vol. 95, no. 26, pp. 15293-15298, 1998.

[16] S. Güttinger, P. Mühlhäusser, R. Koller-Eichhorn, J. Brennecke, and U. Kutay, "Transporting functions as importin and mediates nuclear import of HuR," Proceedings of the National Academy of Sciences of the United States of America, vol. 101, no. 9, pp. 2918-2923, 2004.

[17] I.-E. Gallouzi and J. A. Steitz, "Delineation of mRNA export pathways by the use of cell-permeable peptides," Science, vol. 294, no. 5548, pp. 1895-1901, 2001.

[18] A. Rebane, A. Aab, and J. A. Steitz, "Transportins 1 and 2 are redundant nuclear import factors for hnRNP A1 and HuR," RNA, vol. 10, no. 4, pp. 590-599, 2004.

[19] N. S. Levy, S. Chung, H. Furneaux, and A. P. Levy, "Hypoxic stabilization of vascular endothelial growth factor mRNA by the RNA-binding protein HuR," Journal of Biological Chemistry, vol. 273, no. 11, pp. 6417-6423, 1998.

[20] W. Wang, H. Furneaux, and H. Cheng et al., "HuR regulates p21 mRNA stabilization by UV light," Molecular and Cellular Biology, vol. 20, no. 3, pp. 760-769, 2000.

[21] W. Wang, M. C. Caldwell, S. Lin, H. Furneaux, and M. Gorospe, "HuR regulates cyclin A and cyclin B1 mRNA stability during cell proliferation," EMBO Journal, vol. 19, no. 10, pp. 2340-2350, 2000.

[22] L. B. Nabors, G. Y. Gillespie, L. Harkins, and P. H. King, "HuR, a RNA stability factor, is expressed in malignant brain tumors and binds to adenine- and uridine-rich elements within the $3^{\prime}$ untranslated regions of cytokine and angiogenic factor mRNAs," Cancer Research, vol. 61, no. 5, pp. 2154-2161, 2001.

[23] M. Kullmann, U. Göpfert, B. Siewe, and L. Hengst, "ELAV/Hu proteins inhibit p27 translation via an IRES element in the p27 5'UTR," Genes and Development, vol. 16, no. 23, pp. 30873099, 2002.

[24] K. Mazan-Mamczarz, S. Galbán, and I. López de Silanes et al., "RNA-binding protein HuR enhances p53 translation in response to ultraviolet light irradiation," Proceedings of the National Academy of Sciences of the United States of America, vol. 100, no. 14, pp. 8354-8359, 2003.

[25] A. Lal, K. Mazan-Mamczarz, T. Kawai, X. Yang, J. L. Martindale, and M. Gorospe, "Concurrent versus individual binding of HuR and AUF1 to common labile target mRNAs," EMBO Journal, vol. 23, no. 15, pp. 3092-3102, 2004.

[26] A. Lal, T. Kawai, X. Yang, K. Mazan-Mamczarz, and M. Gorospe, "Antiapoptotic function of RNA-binding protein HuR effected through prothymosin $\alpha$," EMBO Journal, vol. 24, no. 10 , pp. 1852-1862, 2005.

[27] K. Abdelmohsen, R. Pullmann Jr., and A. Lal et al., "Phosphorylation of HuR by Chk2 regulates SIRT1 expression," Molecular Cell, vol. 25, no. 4, pp. 543-557, 2007.

[28] K. Abdelmohsen, A. Lal, H. H. Kim, and M. Gorospe, "Posttranscriptional orchestration of an anti-apoptotic program by HuR," Cell Cycle, vol. 6, no. 11, pp. 1288-1292, 2007.

[29] H. H. Kim, K. Abdelmohsen, and A. Lal et al., "Nuclear HuR accumulation through phosphorylation by Cdk1," Genes and Development, vol. 22, no. 13, pp. 1804-1815, 2008.

[30] H. H. Kim, Y. Kuwano, S. Srikantan, E. K. Lee, J. L. Martindale, and M. Gorospe, "HuR recruits let-7/RISC to repress c-Myc expression," Genes and Development, vol. 23, no. 15, pp. 17431748, 2009. 
[31] I. López de Silanes, M. Zhan, A. Lal, X. Yang, and M. Gorospe, "Identification of a target RNA motif for RNA-binding protein HuR," Proceedings of the National Academy of Sciences of the United States of America, vol. 101, no. 9, pp. 2987-2992, 2004.

[32] I. López de Silanes, J. Fan, and X. Yang et al., "Role of the RNAbinding protein HuR in colon carcinogenesis," Oncogene, vol. 22, no. 46, pp. 7146-7154, 2003.

[33] M. Gorospe, "HuR in the mammalian genotoxic response: post-transcriptional multitasking," Cell Cycle, vol. 2, no. 5, pp. 412-414, 2003.

[34] A. Figueroa, A. Cuadrado, and J. Fan et al., "Role of HuR in skeletal myogenesis through coordinate regulation of muscle differentiation genes," Molecular and Cellular Biology, vol. 23, no. 14, pp. 4991-5004, 2003.

[35] K. van der Giessen, S. Di-Marco, E. Clair, and I. E. Gallouzi, "RNAi-mediated HuR depletion leads to the inhibition of muscle cell differentiation," Journal of Biological Chemistry, vol. 278, no. 47, pp. 47119-47128, 2003.

[36] V. Katsanou, O. Papadaki, and S. Milatos et al., "HuR as a negative posttranscriptional modulator in inflammation," Molecular Cell, vol. 19, no. 6, pp. 777-789, 2005.

[37] K. Abdelmohsen, Y. Kuwano, H. H. Kim, and M. Gorospe, "Posttranscriptional gene regulation by RNA-binding proteins during oxidative stress: implications for cellular senescence," Biological Chemistry, vol. 389, no. 3, pp. 243-255, 2008.

[38] K. Abdelmohsen, S. Srikantan, and X. Yang et al., "Ubiquitinmediated proteolysis of HuR by heat shock," EMBO Journal, vol. 28, no. 9, pp. 1271-1282, 2009.

[39] A. Basu, "Involvement of protein kinase C- $\delta$ in DNA damage-induced apoptosis," Journal of Cellular and Molecular Medicine, vol. 7, no. 4, pp. 341-350, 2003.

[40] H. H. Kim, X. Yang, Y. Kuwano, and M. Gorospe, "Modification at $\mathrm{HuR}(\mathrm{S} 242)$ alters $\mathrm{HuR}$ localization and proliferative influence," Cell Cycle, vol. 7, no. 21, pp. 3371-3377, 2008.

[41] A. Doller, A. Huwiler, R. Müller, H. H. Radeke, J. Pfeilschifter, and W. Eberhardt, "Protein kinase $\mathrm{C} \alpha$-dependent phosphorylation of the mRNA-stabilizing factor HuR: implications for posttranscriptional regulation of cyclooxygenase-2," Molecular Biology of the Cell, vol. 18, no. 6, pp. 2137-2148, 2007.

[42] K. Subbaramaiah, T. P. Marmo, D. A. Dixon, and A. J. Dannenberg, "Regulation of cyclooxgenase-2 mRNA stability by taxanes: evidence for involvement of p38, MAPKAPK-2, and HuR," Journal of Biological Chemistry, vol. 278, no. 39, pp. 37637-37647, 2003.

[43] Y. Kuwano, H. H. Kim, and K. Abdelmohsen et al., "MKP-1 mRNA stabilization and translational control by RNA-binding proteins HuR and NF90," Molecular and Cellular Biology, vol. 28, no. 14, pp. 4562-4575, 2008.

[44] R. Mazroui, S. Di Marco, and E. Clair et al., "Caspasemediated cleavage of HuR in the cytoplasm contributes to pp32/PHAP-I regulation of apoptosis," Journal of Cell Biology, vol. 180, no. 1, pp. 113-127, 2008.

[45] H. Niida and M. Nakanishi, "DNA damage checkpoints in mammals," Mutagenesis, vol. 21, no. 1, pp. 3-9, 2006.

[46] M. B. Kastan and D.-S. Lim, "The many substrates and functions of ATM," Nature Reviews Molecular Cell Biology, vol. 1, no. 3, pp. 179-186, 2000.

[47] W. A. Cliby, C. J. Roberts, and K. A. Cimprich et al., "Overexpression of a kinase-inactive ATR protein causes sensitivity to DNA-damaging agents and defects in cell cycle checkpoints," EMBO Journal, vol. 17, no. 1, pp. 159-169, 1998.

[48] R. S. Tibbetts, K. M. Brumbaugh, and J. M. Williams et al., "A role for ATR in the DNA damage-induced phosphorylation of p53," Genes and Development, vol. 13, no. 2, pp. 152-157, 1999.

[49] B. Shiotani and L. Zou, "Single-stranded DNA orchestrates an ATM-to-ATR switch at DNA breaks," Molecular Cell, vol. 33, no. 5, pp. 547-558, 2009.

[50] Y. Shiloh and M. B. Kastan, "ATM: genome stability, neuronal development, and cancer cross paths," Advances in Cancer Research, vol. 83, pp. 209-254, 2001.

[51] N. Motoyama and K. Naka, "DNA damage tumor suppressor genes and genomic instability," Current Opinion in Genetics and Development, vol. 14, no. 1, pp. 11-16, 2004.

[52] H. Zhao and H. Piwnica-Worms, "ATR-mediated checkpoint pathways regulate phosphorylation and activation of human Chk1," Molecular and Cellular Biology, vol. 21, no. 13, pp. 4129-4139, 2001.

[53] J. Jin, T. Shirogane, and L. Xu et al., "SCF $\beta$-TRCP links Chk1 signaling to degradation of the Cdc25A protein phosphatase," Genes and Development, vol. 17, no. 24, pp. 3062-3074, 2003.

[54] M. Donzelli and G. F. Draetta, "Regulating mammalian checkpoints through Cdc25 inactivation," EMBO Reports, vol. 4, no. 7, pp. 671-677, 2003.

[55] J. Lee, A. Kumagai, and W. G. Dunphy, "Positive regulation of Weel by Chk1 and 14-3-3 proteins," Molecular Biology of the Cell, vol. 12, no. 3, pp. 551-563, 2001.

[56] M. Enomoto, H. Goto, and Y. Tomoro et al., "Novel positive feedback loop between Cdk1 and Chk1 in the nucleus during G2/M transition," Journal of Biological Chemistry, vol. 284, no. 49, pp. 34223-34230, 2009.

[57] V. A. J. Smits, P. M. Reaper, and S. P. Jackson, "Rapid PIKKdependent release of Chk1 from chromatin promotes the DNA-damage checkpoint response," Current Biology, vol. 16, no. 2, pp. 150-159, 2006.

[58] A. Doller, E.-S. Akool, and A. Huwiler et al., "Posttranslational modification of the AU-rich element binding protein HuR by protein kinase $\mathrm{C} \delta$ elicits angiotensin II-induced stabilization and nuclear export of cyclooxygenase 2 mRNA," Molecular and Cellular Biology, vol. 28, no. 8, pp. 2608-2625, 2008.

[59] B.-B. S. Zhou and S. J. Elledge, "The DNA damage response: putting checkpoints in perspective,” Nature, vol. 408, no. 6811, pp. 433-439, 2000.

[60] H. C. Reinhardt and M. B. Yaffe, "Kinases that control the cell cycle in response to DNA damage: Chk1, Chk2, and MK2," Current Opinion in Cell Biology, vol. 21, no. 2, pp. 245-255, 2009.

[61] J. Bartek, J. Falck, and J. Lukas, "Chk2 kinase-a busy messenger," Nature Reviews Molecular Cell Biology, vol. 2, no. 12, pp. 877-886, 2001.

[62] D. W. Bell, J. M. Varley, and T. E. Szydlo et al., "Heterozygous germ line hCHK2 mutations in Li-Fraumeni syndrome," Science, vol. 286, no. 5449, pp. 2528-2531, 1999.

[63] P. Vahteristo, J. Bartkova, and H. Eerola et al., "A CHEK2 genetic variant contributing to a substantial fraction of familial breast cancer," American Journal of Human Genetics, vol. 71, no. 2, pp. 432-438, 2002.

[64] X. Wu, S. R. Webster, and J. Chen, "Characterization of tumorassociated Chk2 mutations," Journal of Biological Chemistry, vol. 276, no. 4, pp. 2971-2974, 2001.

[65] A. Doller, K. Schlepckow, H. Schwalbe, J. Pfeilschifter, and W. Eberhardt, "Tandem phosphorylation of serines 221 and 318 by protein kinase $\mathrm{C} \delta$ coordinates mRNA binding and nucleocytoplasmic shuttling of HuR," Molecular and Cellular Biology, vol. 30, no. 6, pp. 1397-1410, 2010. 
[66] A. Doller, J. Pfeilschifter, and W. Eberhardt, "Signalling pathways regulating nucleo-cytoplasmic shuttling of the mRNAbinding protein HuR," Cellular Signalling, vol. 20, no. 12, pp. 2165-2173, 2008.

[67] K. Yoshida, "Nuclear trafficking of pro-apoptotic kinases in response to DNA damage," Trends in Molecular Medicine, vol. 14, no. 7, pp. 305-313, 2008.

[68] Á. Molnár, A. M. Theodoras, L. I. Zon, and J. M. Kyriakis, "Cdc42Hs, but not Rac1, inhibits serum-stimulated cell cycle progression at G1/S through a mechanism requiring p38/RK," Journal of Biological Chemistry, vol. 272, no. 20, pp. 1322913235, 1997.

[69] A. Cuenda and S. Rousseau, "p38 MAP-kinases pathway regulation, function and role in human diseases," Biochimica et Biophysica Acta, vol. 1773, no. 8, pp. 1358-1375, 2007.

[70] T. M. Thornton and M. Rincon, "Non-classical p38 map kinase functions: cell cycle checkpoints and survival," International Journal of Biological Sciences, vol. 5, no. 1, pp. 44-52, 2009.

[71] V. Lafarga, A. Cuadrado, I. López de Silanes, R. Bengoechea, O. Fernandez-Capetillo, and A. R. Nebreda, "p38 mitogenactivated protein kinase- and HuR-dependent stabilization of p21Cip1 mRNA mediates the G1/S checkpoint," Molecular and Cellular Biology, vol. 29, no. 16, pp. 4341-4351, 2009.

[72] H. Tran, F. Maurer, and Y. Nagamine, "Stabilization of urokinase and urokinase receptor mRNAs by HuR is linked to its cytoplasmic accumulation induced by activated mitogenactivated protein kinase-activated protein kinase 2," Molecular and Cellular Biology, vol. 23, no. 20, pp. 7177-7188, 2003.

[73] W. Wang, X. Yang, and T. Kawai et al., "AMP-activated protein kinase-regulated phosphorylation and acetylation of importin $\alpha 1$ : involvement in the nuclear import of RNA-binding protein HuR," Journal of Biological Chemistry, vol. 279, no. 46, pp. 48376-48388, 2004.

[74] H. H. Kim and M. Gorospe, "Phosphorylated HuR shuttles in cycles," Cell Cycle, vol. 7, no. 20, pp. 3124-3126, 2008.

[75] K. Abdelmohsen, S. Srikantan, Y. Kuwano, and M. Gorospe, "miR-519 reduces cell proliferation by lowering RNA-binding protein HuR levels," Proceedings of the National Academy of Sciences of the United States of America, vol. 105, no. 51, pp. 20297-20302, 2008.

[76] K. Abdelmohsen, M. M. Kim, S. Srikantan, et al., "miR-519 suppresses tumor growth by reducing HuR levels," Cell Cycle, vol. 9, no. 7, pp. 1354-1359, 2010.

[77] K. Abdelmohsen and M. Gorospe, "Post-transcriptional regulation of cancer traits by HuR," WIRES RNA. In press. 

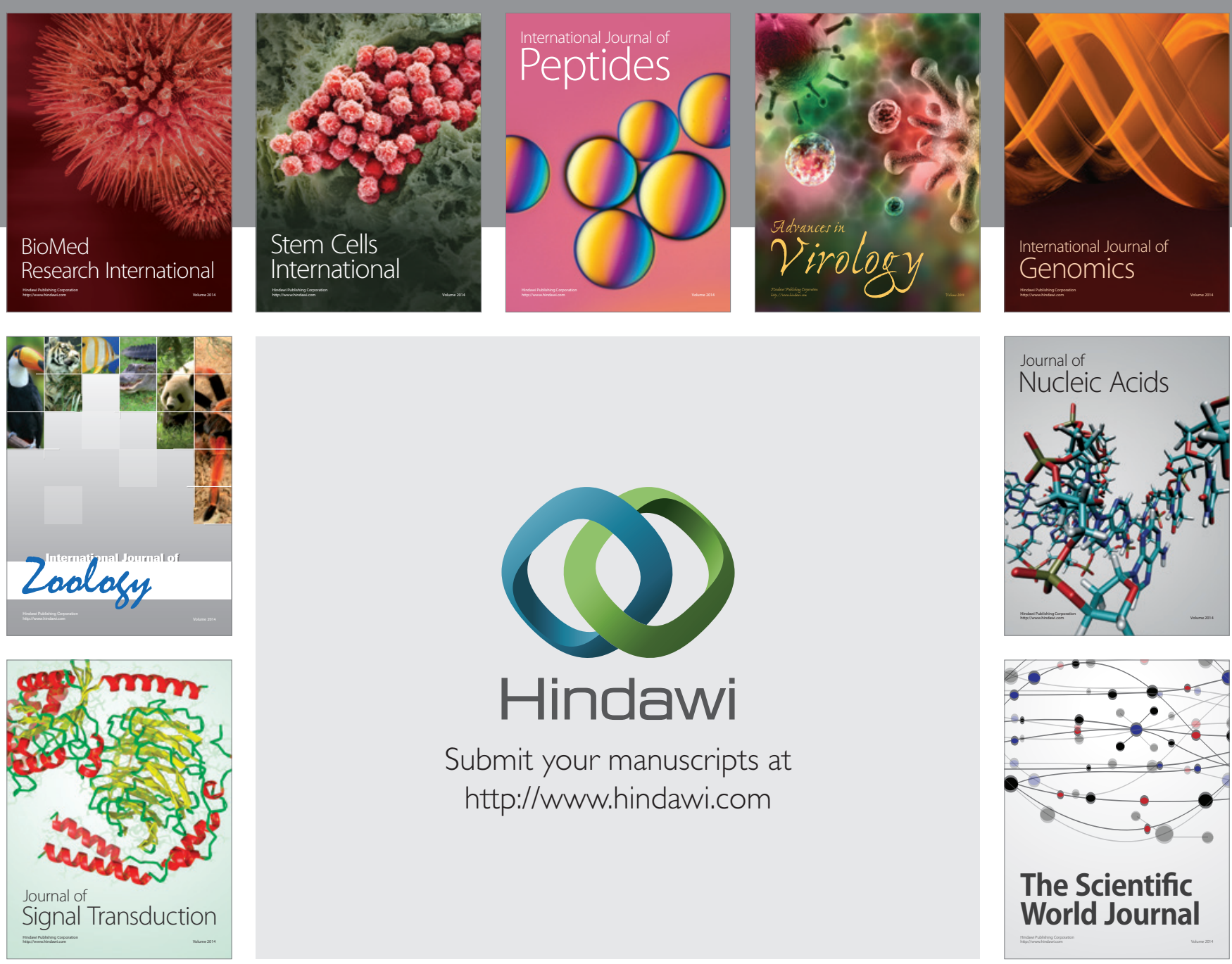

Submit your manuscripts at

http://www.hindawi.com
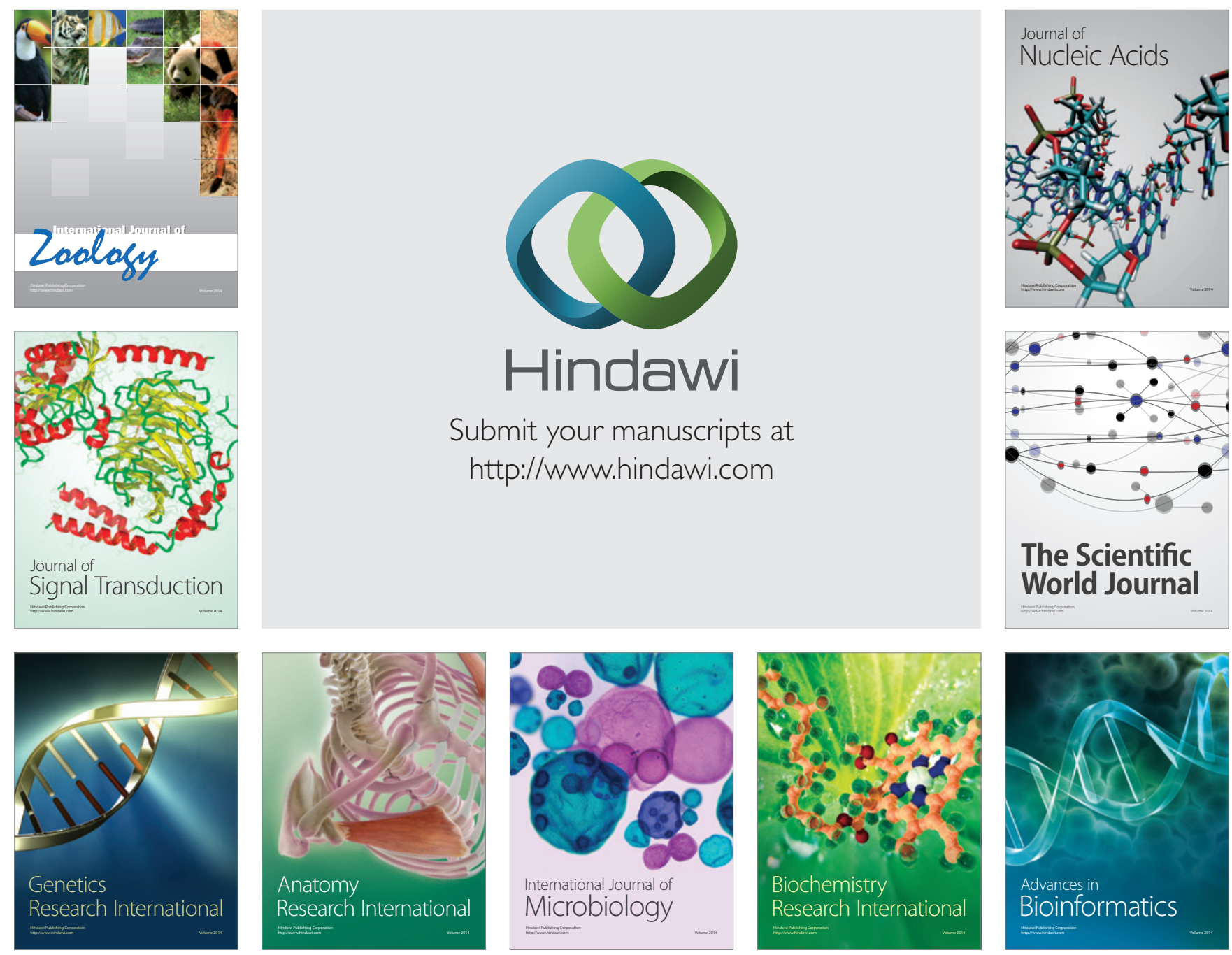

The Scientific World Journal
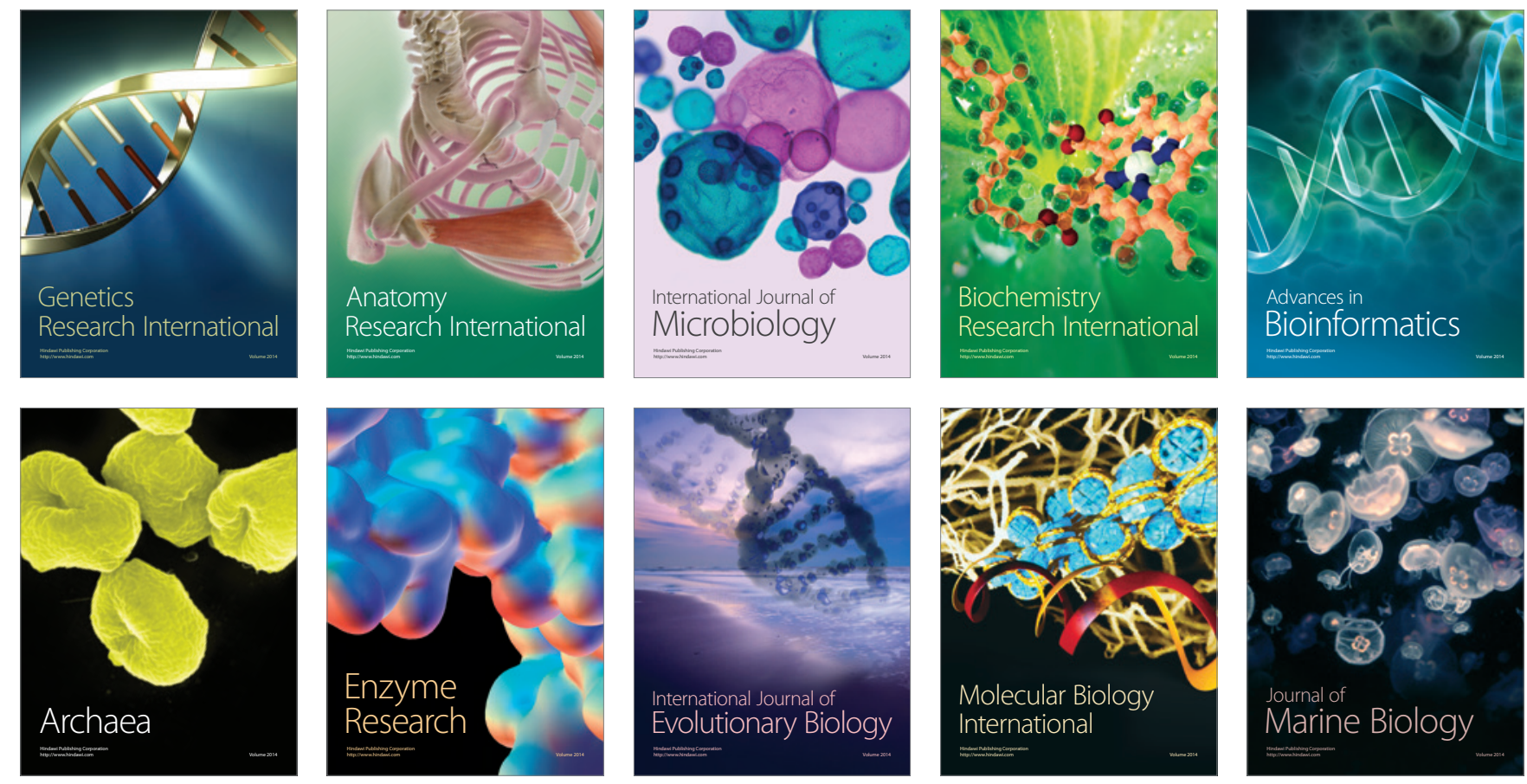